\title{
Efficiency of Formation Informative and Communicative Competence of Future Doctors in Teaching Foreign Languages
}

\author{
Dilara Zhuasbekovna Ernazarova, Indira Useinovna Bekbolatova, \\ Kamalbek Meirbekovich Berkimbaev, Saltanat Tynybekovna Nyshanova \\ and Parida Kuandykovna Iskakova
}

\author{
Ahmed Yasawi International Kazakh-Turkish University, 29 B. \\ Sattarkhanov Avenue, 161200 Turkistan, Kazakhstan.
}

DOI: http://dx.doi.org/10.13005/bbra/1940

(Received: 10 August 2015; accepted: 15 October 2015)

\begin{abstract}
In the Annual appeal to the Nation by the President of the Republic of N.A. Nazarbayev competitiveness has been marked as the main indicator of the desired development of the Republic of Kazakhstan. Competitive professional education is determined by, in addition to the image of the university, prices, availability, mobility, educational services institution, above all, their quality. Education of the future takes on the features of innovative education integrated with research activity, characterized by a continuous, fundamental, practical orientation. Basis for the formation of the future of education is to ensure and guarantee the quality of education. Increased attention to the problems of the quality of education is ubiquitous priority for educational institutions and a global problem. All countries are wondering how to ensure quality of education in terms of its accessibility and rapidly changing labor market situation. Management of educational process in the IKTU by A. Yassawi initially modeled as a multi-level system that allows an objective and timely assesses of the level of training of future physicians. The department paid great attention to not only the implementation of training programs, but also the implementation of a comprehensive quality control of student learning. Improving the forms and methods of final control is an important factor in the quality management system of higher education in medical school. The introduction of educational technology assessment of professional competence of medical school graduates in practice proved to be effective. Modern trends in planning, organizing, evaluating the quality of education actually helped to ensure the implementation of competence-based approach in the training of doctors.
\end{abstract}

Key words: Innovative education, future doctors, process of teaching of foreign language.

Actuality of research is defined by requirement of system of formation of information and communicative competence of future doctors, need of creation of complete system of formation of information and communicative competence of future doctors; improvement of knowledge of a foreign language and development of the

\footnotetext{
* To whom all correspondence should be addressed.

E-mail: Kamalbek.Berkimbaev@iktu.kz, mail.dilya@mail.ru,saltanur@mail.ru
}

contents, forms, methods and tutorials with application of information technologies.

Today in the field of health care of the Republic of Kazakhstan, based on a basis of new progressive technologies, is in great need in experts of a new formation with wide information and communicative competence and fundamental knowledge for implementation of breakthrough projects of the state from the area of medical services (State Program for Development of Education of the Republic of Kazakhstan for 20112020, www.edu.gov.kz). 
Modernization of the state relies on modernization of education, on its substantial and structural updating. Not system of knowledge, skills, and set of basic competences in intellectual, communication, information and other spheres has to become primary activity of educational institution. The changes of the higher education plays a more and more important role and becomes pledge of successful self-realization of the person in modern society (Gillotti et al., 2002).

The effectiveness of training is one of the indicators of the quality of education, as the extent to which the results and learning objectives (Scrivener, 2011). Effectiveness and efficiency of learning can be defined and measured only by means of monitoring and evaluation of acquired knowledge, skills, competencies, so monitoring and evaluation of knowledge of students is one of the most important and mandatory components of the learning process.

Therefore, at the present stage is particularly relevant question of the need to create and implement monitoring and evaluation systems of knowledge, allowing to identify the real level of professional competence of medical students (Berkimbaev \& Ernazarova, 2012)

When developing an objective approach to assessing the quality of higher education should be to clarify the concept and main functions of monitoring and evaluation. In the most general definition pedagogical control is the process of identifying, measuring and evaluation of knowledge and skills of students. Broadly defined, objective control of the learning outcomes is "an effective means of creating a viable methods of mental activity and the practical skills of students, proper development of their abilities and inclinations, stimulating cognitive activity; it educates the students a sense of responsibility for the results of their academic work, helps the formation of his her personality. In addition, testing of knowledge and skills and performs the function of teaching is an effective tool for determining the effectiveness of pedagogical work" (Peterwagner, 2005).

Control of students' knowledge plays the role of feedback, because regular check stimulates students, disciplines and forms a sense of responsibility for the performance of their teaching duties (Berkimbaev \& Kerimbaeva, 2010). In addition, the systematic control of knowledge helps to establish a timely inconsistencies and gaps in the knowledge of students, which helps the effective management of the quality of education.

A great place to research the authors paid to the definition of control functions. It identifies the following functions of pedagogical control: *developing;

*diagnostic.

The main function is diagnostic, aimed at measuring the level of knowledge of students at all stages of the learning process. In addition, the results of monitoring in addition to allow the level of mastering the curriculum for students and evaluate the effectiveness of teaching methods, as well as the effectiveness of the control method (Matyash, 2011). In addition to these functions, you can select another monitoring control function that provides tracking and timely monitoring of the learning process and is designed to implement the principle of information quality education.

The monitoring function detects the level of control of Learning, typical and individual mistakes students at each grade level and provides a reliable feedback.

In present time information technologies significantly changed all parts of human life and, apparently, most, it belongs to essential increase of productivity of intellectual work (Bimaganbetova et.al., 2013). Today every competent specialist of this or that profession has to use effectively possibilities of information technologies in the professional activity and know foreign languages.

\section{Aim and Research Problems}

One of the main tasks facing the system of preparation of future specialists is improvement of quality of professional training taking into account the modern directions of development and using of information technologies in professional activity.

\section{Research problems}

To analyze a condition of a problem of formation of information and communicative competence of future doctors in the course of training a foreign language with application of information technologies in higher education institution, to reveal degree of its theoretical and practical readiness on the basis of experimental check and analyses of comparison experimental 
and control groups of trainees of "English for Medical Specialties" of Medical faculty of H.A.Yasawi International Kazakh-Turkish University, on specialties the 5B130100-General medicine; to prove requirement and need of formation of information and communicative competence of future doctors as preparation making professionally, to develop model of formation of information and communicative competence of future doctors using means of a foreign language and to prove efficiency of application of information technologies in educational process.

In vocational education, there are several types of control: basic, current, landmark, overall, differing in stages in the course of the learning process.

The purpose of monitoring is to identify the underlying source of knowledge and skills and the identification of gaps in them. It is held at the beginning of cycle classes in a certain discipline in oral or written form on a pre-prepared teacher issues.

Monitoring is carried out daily on the theme of employment. Availability monitoring is designed to stimulate cognitive and learning activity of students, as well as identifying and filling gaps in education, to determine the effectiveness of educational programs and activities of the teacher (Lekhin \& Petrov, 1952).

This control aims to assess the assimilation of the curriculum, it is desirable to control held senior lecturer or senior lecturer. In medical education, along with the assessment of knowledge within the boundary control are evaluated as communication skills of the student, his her ability to carry out a physical examination and differential diagnosis and treatment (senior courses) (Blauberg \& Pantinin, 1982).

The main objective of total control measurement and evaluation of students' knowledge learned. The final control can be carried out on completion of the program of discipline, but it can be as a qualifying exam.

The main principles of monitoring learning outcomes are:

* Objectivity, which is evidence-based content control tasks, issues, even, friendly attitude to all students in the sciences, the adequacy of the criteria for assessment of knowledge and skills (Rapatsevich, 2001); Systematic, which manifests itself in the need for diagnostic monitoring at all stages of the educational process;

* Visibility (publicity), which is to hold open trials of all trainees on the same criteria. The principle of transparency requires the announcement of assessments, as assessment - a benchmark by which trainees are judged on the benchmark requirements for them, as well as the objectivity of the teacher.

The logical result of monitoring is to assess learning outcomes. Monitoring and evaluation - interdependent concepts as assessment is a way of expressing control, and control is a primary function of evaluation (Baydenko \& Zantvort, 2003). It controls the evaluation function is a mechanism for effective management of the learning process and the quality of educational services.

It should be noted that monitoring and evaluation exercise management training activities and appear in a phased verification solution of educational problems, the analysis of the achievements and mistakes of students, final evaluation of their results, as well as in the choice of the form and content of education at all its stages (Raven, 2002).

Many authors consider the notion of “pedagogical supervision” and "educational evaluation" adequate, since control is based on learning outcomes according to the normalized standard, educational standards specific curriculum and assessment is achieved by comparing the level of knowledge of students with standard concepts described in the curriculum. So, by Sh. Amonashvili's definition, assessment is "a process of correlating the results with the planned activities of the standard" (Khutorskiy, 2003).

V.M. Polonsky under evaluation understands "a systematic process consisting in determining the extent to which the acquired knowledge and skills of pre-planned.” The author defines the evaluation process as consisting of the following steps: first of all, the definition of learning objectives; then the choice of control tasks, checking the achievement of these objectives; and finally as the expression marker test results (Hasan, 2003). 
The mark is the final stage of the evaluation process and one of the possible results of evaluations are expressed in semi-formal scores.

The assessment should be placed at the level and quality of knowledge, but not by way of reward or punishment. Requirements for assessment should be optimal unacceptable impact on the assessment of the negative attitude of the teacher to a particular student. There are several methods for the scoring, the most democratic of which are the following methods:

* Teacher introduces students to the criteria on which it is going to evaluate their knowledge. In this case, together with the students discussed the criteria for assessment;

* $\quad$ At the end of the job for it puts two estimates - by the teacher and the student. It is useful for students to self-assess their learning outcomes and compared with the assessment of the teacher;

* Sometimes the teacher has the right to make an assessment "on credit" against future achievements of the student. This method is used in contentious situations, and implies that the student subsequently objectively raise their level of knowledge.

\section{Research objective}

To provide process of formation of information and communicative competence of future doctors and improvement of quality of their professional training on the basis of theoretical and practical development and experimental check of system of training to a foreign language of future doctors with means of information technologies (Semenov, 2006).

The Use of information technologies in training in a foreign language allows those being trained to have access to a wide range of modern information for the purpose of development of various competences.

Information and communicative competence is considered by us as system of the internal resources necessary for creation of effective communicative action in a circle of situations of professional, interpersonal and crosscultural interaction. The communicative professional act includes the analysis and assessment of the situation, formation of the purpose and operational structure of action, implementation of the plan or its correction, an efficiency assessment. From here, information and communicative competence is an ability to use a foreign language successfully, to work with its help on the basis of practical experience, ability and knowledge at the solution of professional tasks.

Information and communicative competence of future doctors has to include the cognitive activity, creative and behavioral and emotional components formed in the course of language preparation with use of a complex of lingvo linguo didactical means and means of interactive lingvo-information support. As at the base of formation of information and communicative competence lay competence-based approach, the interrelation between using and learning of foreign language is established in it. Use of the language and its studying include actions of the person in the course of which performance develops a number of competences: professional and communicative (Berkimbaev \& Kerimbaeva, 2012). They provide the solution of professional tasks in various conditions taking into account various restrictions and are realized in kinds of activity and the actions directed on perception of texts, in connection with certain subjects and spheres of communication and with application of the corresponding strategy. The accounting of these processes by conducts to further development and modification of these competences.

Available information support allows to train a work bases at the computer at the initial stage of training, and then to become the advanced users of applied programs, to seize professional skills.

At the present stage at International Kazakh-Turkish University by A.Yasawi, in particular in the 5B130100-General medicine at English lessons new techniques with use of information and computer technologies which are opposed to traditional training are used.

In the course of formation of information - communicative competence of students in the 5B130100- General medicine they rather actively are interested in information and computer and Internet technologies, the Internet in this case acts as excellent means for development of their creative abilities. The main advantages of using the Internet - technologies are: increase of interest to training; 
independence development; responsibility and commitment development.

To teach future doctors to communication in a foreign language it is necessary to create real life situations which will stimulate to material studying, and to develop adequate behavior.

To train future doctors successfully to speak a foreign language it is necessary to awaken interest to a studied subject and systematically to support it. In this regard there is a problem of comprehensive and careful study of ways of obtaining information (Berkimbaev et.al., 2012).

Now there is an active transition to information type of society, informatization of education is considered as a necessary condition of development of the personality at the present stage. It is important that on lessons of a foreign language felt beauty of a foreign language. Use of various active forms and work methods for this purpose is possible. All this develops independence in language studying, forms information, language and communicative competences of future experts, promotes development of analytical skills.

Future doctors have to be competitive, demanded on a labor market. Therefore also the purposes of education are defined, first of all, on the basis of requirements of the training program to knowledge and abilities and the demands made by society to development and good breeding of new generation. Future experts have to be able independently, actively work, make decisions, flexibly adapt for changing living conditions.

Research methods: the analysis of scientific literatureon psychology, medicine, a technique of teaching of a foreign language; supervision, questioning, testing, carrying out skilled training, pedagogical experiment, analysis and processing of statistical data.

Theoretical and practical importance: to revealand prove a complex of the organizational and pedagogical, psychological-pedagogical, didactical-methodical conditions promoting efficiency of formation of information and communicative competence of future doctors and improvement of quality of their professional training in the course of training in a foreign language by means of information technologies. To develop system of exercises and the tasks intended for the organization of a practical training on medicine in English and components of formation of information and communicative competence of future doctors in the course of training in a foreign language by means of information technologies.

\section{RESULTS AND DISCUSSION}

The Results of the experiment showed that modern educational process of vocational training of future doctors is focused mainly on development of creative and professional and technological

Table 1. Level of formation of information and communicative competence before the experiment (on levels), \%

\begin{tabular}{lccrcr}
\hline \multirow{2}{*}{ Level } & \multicolumn{2}{c}{ Control group } & & \multicolumn{2}{c}{ Experimental group } \\
\cline { 2 - 3 } \cline { 5 - 5 } & Before the experiment & After the experiment & & Before the experiment & After the experiment \\
\hline High & 5.6 & 5.7 & 13.3 & 8.7 \\
Medium & 38.1 & 46.2 & 33.4 & 78.0 \\
low & 56.3 & 48.1 & 53.3 & 13.3 \\
\hline
\end{tabular}

Table 2. Expert assessment of formation of information and communicative competence of future doctors before the pedagogical experiment (on levels), \%

\begin{tabular}{|c|c|c|c|c|}
\hline \multirow[t]{2}{*}{ Level } & \multicolumn{2}{|c|}{ Control group } & \multicolumn{2}{|c|}{ Experimental group } \\
\hline & Before the experiment & After the experiment & Before the experiment & After the experiment \\
\hline High & 33.3 & 26.7 & 33.3 & 7.7 \\
\hline Medium & 53.3 & 60.0 & 46.7 & 38.0 \\
\hline low & 13.3 & 13.3 & 20.0 & 54.3 \\
\hline
\end{tabular}


qualities of future doctors. Educational practice showed that competence-based approach in educational process of higher education institution promotes formation of information and communicative competence of future doctors.

At the forming stage of experimental work on the basis of A.Yasawi International KazakhTurkish University were created two identical groups of the students who study in "Medical care". We used the method of research experiment on approbation of conditions of formation of information and communicative competence of future doctors acted. Educational process in experimental group was constructed according to a hypothesis of our research. As experimental variable information technologies in the course of training in a foreign language were applied, and also were introduced reasonable pedagogical conditions of formation of information and communicative competence of future doctors. The control group was engaged in the conditions of traditional educational process.

the Level of formation of information and communicative competence of future doctors was estimated by three criteria (cognitive, emotional and moral, operational and activity) according to the chosen structure of these qualities and the logic of experimental work. Thus cognitive and emotional and moral qualities of the identity of future doctors were investigated by means of tests, and for an assessment of level of formation of information and communicative competence of future doctors the method of control and total cuts was used.

Results of the forming stage of experimental work showed that in the experimental groups there is a complete formation of information and communicative competence of future doctors, possessing system of professionally significant qualities and competences.

The Efficiency of the revealed pedagogical conditions of formation of information and communicative competence of future doctors in the course of learning of the foreign language with application of information technologies is confirmed by results of research (tab. 1).

Results of a complex assessment of level of formation of information and communicative competence of future doctors by results of control and total test (tab. 2) also show noticeable positive dynamics of formation of information and communicative competence of future doctors who are training in experimental group in comparison with the control group.

Statistical processing of results of research was carried out with use of the following methods: calculation of coefficient of correlation across; pair two-selective t-criterion; the twoselective t-test with identical dispersions, criterion $\div 2$. At research of a professional standard of future doctors value $\div 2$ made 14.58 , and at an assessment of formation of information and communicative competence of future doctors by results of total and control cuts $-15,00$.

Thus, the results of experimental work proved efficiency and sufficiency of the pedagogical conditions of formation of information and communicative competence of future doctors laid down by us in learning of foreign language with application of information technologies. Use of methods of mathematical statistics confirms reliability and the importance of the obtained experimental data. Thus development of all revealed professional qualities of future doctors in experimental and pedagogical conditions confirms the theoretical provision put forward by us on interconditionality of processes of formation of professional abilities and formation of information and communicative competence of future doctors.

Results of experimental work are based on development of methodical recommendations about the organization of process of learning of foreign language and the vocational training, directed on formation of information and communicative competence of future doctors.

\section{CONCLUSION}

The carried-out analysis of research showed efficiency and need of application of information technologies for formation of information and communicative competence of future doctors in the course of training a foreign language, for the solution of educational tasks, formation of the expert with the critical and creative thinking, capable effectively to function in changing conditions of professional activity.

Competence-based approach and application of information technologies promote 
formation of information and communicative competence of future doctors, readiness to enter innovations, to work in non-standard situations, openness to the new.

By the results of the scientific and practical research conducted at A.Yasawi International Kazakh-Turkish university the indicator of formation of information and communicative competence of future doctors is readiness for changes which includes understanding of a situation of the new requirement, developments of the strategic reasons estimated for sequence of their application in professional activity, including development of the developed educational processes and revision of the content of educational process.

In conclusion it would be desirable to note that the main info-communicative competences of future doctors are most effectively taught with use of models of communication. Effective training methods of formation of competence of future doctors in learning a foreign language include the role-playing games, situations, work with the standardized patients, and work with real patients. It is necessary to apply registration or direct supervision to maintenance of constructive feedback. Good skills of communication provide effective interaction of the patient and the doctor. Information and communicative competences are not minor addition or elective lines of the professional characteristic. They are necessary and take the central place in effective medical practice.

\section{REFERENCES}

1. State Program for Development of Education of the Republic of Kazakhstan for 2011-2020. www.edu.gov.kz

2. Gillotti C.et.al., Social Science and Medicine, 2002; 54(7): 1011-1023, New communicative technologiesib socialhumanitarian science and education/Pod ob. Red. A.N. Kulika.-M:Logos, 2003 p.424

3. Scrivener, J., Learning Teaching. Macmillan, 2011; 90 -95

4. Berkimbaev, K.M., and Ernazarova, D.Zh., "The question of defining info-communicative competence of future doctor “. International journal of experimental education N8 ISSN 19963947; 2012.
5. Peterwagner, R., What Is the Matter With Communicative Competence?. An Analysis to Encourage Teachers of English to Assess the Very Basis of Their Teaching, Lit Verlag, 2005; $62-70$

6. Berkimbaev, K.M., and Kerimbaeva, B.T., The formation of informational-communicative competence of future teachers in credite system of education.// Al-Farabi Kazakh National university VESTNIK, Educational science 2010; 2-3(30-31): 54-57.

7. Matyash, N.V., Innovative pedagogical technologies: Design training. Moscow: Academy, 2011; 144.

8. Bimaganbetova A.K. et al., Formation of foreign language professional communicative competence of a future specialist. 3rd World Conference on Innovation and Computer Sciences., Antaliya 2013.

9. Lekhin, I.V. and F.N. Petrov, Concise dictionary of foreign words. M: 1952; 191-195.

10. Blauberg, I.V. and I.K. Pantinin, Modern dictionary of philosophy. M: Politizdat, 1982; 431-434.

11. Rapatsevich, Y.S., Modern dictionary on pedagogy. Minsk. The modern word, 2001; 1 928.

12. Baydenko, V.I. and J. Zantvort, Modernization of professional education: modern stage. The European training Foundation. M 2003; 1-201.

13. Raven, J., Competence in modern life. Identification development and implementation. M, 2002; 1-206.

14. Khutorskiy, A.V., Didactic heuristics. Theory and technology of creative learning. M: MSU Publishinghouse, 2003; 1-416.

15. Hasan, B.I., Border competencies: pedagogical imputation and age-claims. Pedagogic of development: key competences and their development, Krasnoyarsk, 2003; 1-307.

16. Semenov, A., Information and communication technologies in general education: theory and practice.. UNESCO, 2006; 1-327.

17. Berkimbaev, K.M. and B.T. Kerimbaeva, To the problem of using internet technologies in forming informational-communicative competence of future specialists. Bulletin of laboratory of mathematical, education and informatization of the peer-reviewed collection of Scientifics. (Volume 2.), Moscow, enu.kz/repository, 2012.

18. Berkimbaev, K.M. et al., The formation of professional competencies of future specialists. New Educational Review. Thomson Reuters Journal Impact Factor 0.149., Poland, 2012. 